\title{
Clinical Characteristics, Histopathology, and Treatment Outcomes of Pythium Keratitis: A Retrospective Cohort Study
}

\author{
Vilavun Puangsricharern (I) ${ }^{1,2}$ \\ Patraramon \\ Chotikkakamthorn (iD ${ }^{2}$ \\ Wasee Tulvatana $\mathbb{D}^{1}$ \\ Thanachaporn Kittipibul ${ }^{2}$ \\ Patchima Chantaren (ID ${ }^{2}$ \\ Usanee Reinprayoon ${ }^{2}$ \\ Ngamjit Kasetsuwan ${ }^{1,2}$ \\ Vannarut Satitpitakul ${ }^{2}{ }^{2}$ \\ Navaporn Worasilchai, ${ }^{3,4}$ \\ Ariya Chindamporn (D) $^{3}$
}

'Department of Ophthalmology, Faculty of Medicine, Chulalongkorn University, Bangkok, Thailand; ${ }^{2}$ Center of Excellence for Cornea and Stem Cell Transplantation, Faculty of Medicine, Chulalongkorn University and King Chulalongkorn Memorial Hospital, Thai Red Cross Society, Bangkok, Thailand; ${ }^{3}$ Department of Microbiology, Faculty of Medicine, Chulalongkorn University, Bangkok, Thailand; ${ }^{4}$ Department of Transfusion Medicine and Clinical Microbiology, Faculty of Allied Health Sciences, Chulalongkorn University, Bangkok, Thailand
Correspondence: Vilavun Puangsricharern Department of Ophthalmology, Faculty of Medicine, Chulalongkorn University, 1873 Rama IV Road, Pathumwan, Bangkok,

Thailand, 10330

Tel +66 83-012-2999

Email vilavun@hotmail.com
Purpose: To identify factors associated with the prognosis in Pythium keratitis.

Patients and Methods: The medical records of 25 patients (26 eyes) diagnosed with Pythium keratitis at a referral institution were reviewed. The demographic and clinical characteristics, treatment, microbiological diagnosis, histopathological features, and outcomes were recorded. The histopathological specimens were reviewed. The patients were divided into a globe removal group and a globe salvage group. Univariate analysis was used to identify factors associated with poor outcomes.

Results: Fifteen eyes (57.7\%) were removed. Patients in the globe removal group were on average 16.4 years older (95\% CI 6.98 to 25.88 ) than those in the globe salvage group, received the first medication (either topical antifungals or antibiotics) later than one day after the onset of symptoms ( $\mathrm{RR}=2.75,95 \% \mathrm{CI} 1.18$ to 6.42 ), and had a maximal diameter of the infiltration area $\geq 6 \mathrm{~mm}(\mathrm{RR}=3.14,95 \% \mathrm{CI} 1.17$ to 8.45$)$. The globe removal group showed satellite, multifocal, or total corneal infiltration patterns $(\mathrm{RR}=2.82,95 \% \mathrm{CI} 1.03$ to 7.74$)$ and a hypopyon ( $\mathrm{RR}=3.43,95 \% \mathrm{CI} 1.26$ to 9.35$)$ as risk factors. The histopathological examination showed a higher density of Pythium in the globe removal group than the globe salvage group (median 376 (interquartile range 323, 620) versus 107 (interquartile range 16, 260) hyphae per high power field; $P=0.035$ ).

Conclusion: The risk of globe removal in patients with Pythium keratitis increased with age, delayed initial topical antifungal or antibiotic treatment, advanced disease at presentation, and dense Pythium hyphae infiltration of the cornea. Early recognition and treatment are critical to successfully eradicate the infection.

Keywords: eye evisceration, eye infections, keratoplasty, penetrating, oomycetes, prognostic factors

\section{Introduction}

Pythium keratitis is a sight-threatening ocular disease caused by Pythium insidiosum, an aquatic oomycete. Incidence of Pythium keratitis were primarily reported in the tropical, subtropical area especially Thailand and India. ${ }^{1-4}$ Direct exposure of the cornea to the zoospores, the infectious form of P.insidiosum, can result in the development of the disease. ${ }^{5}$ According to previous reports, a history of exposure to contaminated water or vegetative material was an important risk factor for acquiring the infection. ${ }^{1,2,6-8}$ Various patterns of infiltration are described in Pythium keratitis, for example, multiple tentacle-like infiltrations, dot-like lesions, and reticular infiltrations. ${ }^{1,2,6,7,9-13}$ 
Pythium keratitis usually progresses rapidly and is unresponsive to common antifungal treatment. The reason is that the oomycetes lack ergosterol, the main target of commonly used antifungal medications, in their cytoplasmic membrane. ${ }^{14}$ Recently, some Pythium keratitis cases were successfully treated with antibiotics, such as minocycline, azithromycin, chloramphenicol, and linezolid. ${ }^{1,15,16}$ There is no standard treatment regimen for Pythium keratitis to date, but most of the patients undergo early therapeutic penetrating keratoplasty (TPK). ${ }^{11}$ Pythium antigen immunotherapy (PIAI) has also been studied, but its efficacy remains controversial. ${ }^{3,8,11}$ The evisceration and enucleation rates in Pythium keratitis range from 53.3\% to $91 \%$ in Thailand. ${ }^{3,4,8,17}$

Some risk factors of Pythium keratitis were previously evaluated, but their effect on the treatment outcome is still inconclusive. ${ }^{1,8}$ In this study, we retrospectively reviewed a series of Pythium keratitis patients and their clinical and histopathological characteristics and treatment outcomes to identify factors associated with globe removal.

\section{Materials and Methods}

We retrospectively reviewed the medical records of patients consecutively diagnosed with Pythium keratitis who received treatment at King Chulalongkorn Memorial Hospital (KCMH), Bangkok, Thailand, between 2006 and 2019. The diagnosis of Pythium keratitis was confirmed by either a positive microbial culture or a positive polymerase chain reaction (PCR) from a corneal scraping or corneal button part after biopsy or TPK. Patients whose document was missing were excluded from this study. The demographic data, clinical characteristics, microbiological diagnosis, treatment details, and outcome of each patient were extracted from the medical records. We divided the eyes into two groups based on the treatment outcome: a globe removal group (enucleation or evisceration) and a globe salvage group.

The study protocol was approved by the Institutional Review Board of the Faculty of Medicine, Chulalongkorn University (Certificate of approval no. 1368/2019, IRB No. 695/62). The requirement for informed consent was waived because of the nature of the study as a retrospective file review. All patient data was maintained with confidentiality. All procedures of the study adhered to the guidelines and principles laid out in the Declaration of Helsinki 1964 and its later amendments.

\section{Baseline and Clinical Characteristics and Outcomes}

The following data were collected: age, sex, comorbidity, occupation, a history of ocular injury, contamination of the eye with water or natural substances (i.e., soil or plant materials), duration from the onset of symptoms to the first medical treatment (either topical antifungals or antibiotics) and from the onset of symptoms to the first TPK, follow-up time, surgical interventions and treatment outcome.

Data on visual acuity and the clinical characteristics described during slit-lamp examination (Topcon SL-D701 with DC4, Topcon Corporation, Tokyo, Japan) were retrieved from the patients' first visit to our hospital. After admission, as part of our treatment protocol, all patients suspected of having Pythium keratitis were immediately treated with either topical natamycin or amphotericin B. The infectious disease unit was consulted subsequently to assess the need for PIAI, oral terbinafine, or voriconazole. One milliliter of a $2 \mathrm{mg} / \mathrm{mL}$ PIA (a crude antigen) solution, prepared according to the protocol by Mendoza et $\mathrm{al}^{18}$ was injected subcutaneously in laboratory-proven cases. Subsequently, six booster doses were scheduled at $0.5,1$, 1.5, 3, 6, and 12 months. For some cases, treatment with PIAI was continued for a year as an adjunct therapy. Complete vaccination varied depending on the hospital course, followup period, and the specialist's discretion.

TPK was planned in patients, who had a poor response to optimal medical therapy, those showing advanced keratitis that extended to the limbus or posterior segment, or those with perforation. ${ }^{17}$ If the infection could not be controlled with these measures, or the patient developed endophthalmitis, evisceration or enucleation was performed.

The following parameters were analyzed: the maximal diameter of the area of corneal infiltration, depth of infiltration, patterns of infiltration, and presence of an epithelial defect or hypopyon. The maximal diameter of the infiltration area and depth of infiltration were classified according to the modified Jones' criteria ${ }^{19}$ to grade the severity of keratitis: diameter $(<2 \mathrm{~mm}, 2-6 \mathrm{~mm},>6 \mathrm{~mm})$, and depth (anterior $1 / 3$ of the cornea, middle stroma, or extension to the posterior $1 / 3$ of the cornea).

\section{Microbiological Examination}

At the patients' initial assessment, a microbiological examination was performed for all eyes by scraping the corneal lesions using a sterile surgical blade No.15. 
Specimens were sent for gram staining, $10 \%$ potassium hydroxide preparation, and cultivation on blood agar, chocolate agar, and Sabouraud dextrose agar. The cornea specimens harvested during TPK were also sent for microbiological examination as described above. P. insidiosum was diagnosed by using culture or a PCR-based assay that amplified the internal transcribed spacer region and cytochrome oxidase II gene. The PCR-product was subsequently subjected to DNA-sequencing analysis. ${ }^{20,21}$

\section{Histopathological Examination}

All specimens were obtained from corneal biopsies, TPK, evisceration, or enucleation. They were fixed in $10 \%$ neutral buffered formalin and sent for histopathological examination. The paraffin-embedded tissues were stained with hematoxylin and eosin, Gomori methenamine silver, and periodic acid-Schiff. As part of this retrospective study, slides were re-evaluated by one pathologist who was unaware of the patient's treatment outcome. The density of the infiltration with the organism was manually and separately counted in the first corneal specimen that was taken out from infected eye either the corneal button or corneal biopsy, as hyphae per high power field (400x) within the field with the highest organism density. The depths of the invasion for both organisms and inflammatory cells were also recorded. Descemet's membranes were classified as intact or involved, perforated, or detached.

\section{Data Management and Statistical Analysis}

Data were collected from patients' case record forms and converted to electronic files using the double-entry technique. The source documents and the electronic data were later cross-checked by two investigators to ensure the accuracy of the data. Demographic data and clinical characteristics were reported using descriptive statistics. Univariate analysis was performed for each variable. Multivariate analysis was not performed because of the small sample size.

Categorical data were compared using Fisher's exact test. The risk ratio (RR) was calculated and reported with the $95 \%$ confidence interval $(95 \% \mathrm{CI})$. Continuous data were compared with the Student's $t$-test and MannWhitney $U$-test. Data analyses were performed using IBM SPSS Statistics for Windows, version 22.0 (IBM Corp., Armonk, N.Y., USA). A $P$-value $<0.05$ was considered to be statistically significant.

\section{Results}

From 2006 to 2019, 26 eyes of 25 patients (14 males, 11 females) were diagnosed with Pythium keratitis at $\mathrm{KCMH}$. All cases had been treated at other hospitals before they were referred to $\mathrm{KCMH}$. The mean age at presentation was 46.1 \pm 14.0 (range 21-73) years. All except one patient were admitted to the hospital. None of patients had alpha-thalassemia. The mean length of hospital stay was $30.9 \pm 11.9$ (range 15-54) days. The mean follow-up time was 3.08 years (ranging from 2 months to 13.5 years). Ten patients were referred from the East of Thailand. Demographic data of patients are summarized in Table 1. The demographic details, clinical features, treatment, and outcome of each patient are described in Supplementary Table 1.

\section{Clinical Characteristics}

All patients except one had unilateral involvement. The patient with bilateral involvement had a history of wastewater contact of both eyes. The patterns of corneal infiltration were examined and classified into four distinct patterns:

(a) Reticular infiltration: single faint lesion in the center with reticular (or tentacle-like) spreading (Figure 1A);

(b) Satellite infiltration: single dense infiltration surrounded by multiple small infiltrations, indistinct edge (Figure 1B);

Table I Demographic Data and Possible Predisposing Factors

\begin{tabular}{|l|c|}
\hline Demographic Data & $\begin{array}{c}\text { No. of Eyes (\%) } \\
(\mathbf{n}=\mathbf{2 6})\end{array}$ \\
\hline $\begin{array}{l}\text { Age group } \\
<40 \text { years } \\
40-60 \text { years } \\
>60 \text { years }\end{array}$ & $\begin{array}{c}12(30.7) \\
6(23.2)\end{array}$ \\
\hline $\begin{array}{l}\text { Comorbidity } \\
\text { Type 2 Diabetes mellitus } \\
\text { Hemoglobin E trait }\end{array}$ & $1(3.8)$ \\
\hline Agriculturist & $15(3.8)$ \\
\hline History of water contamination & $12(46.2)$ \\
\hline History of eye contamination with natural & $13(50.0)$ \\
\hline substances (ie, soil or plant materials) & $10(38.5)$ \\
\hline History of ocular injury & 6 \\
\hline
\end{tabular}




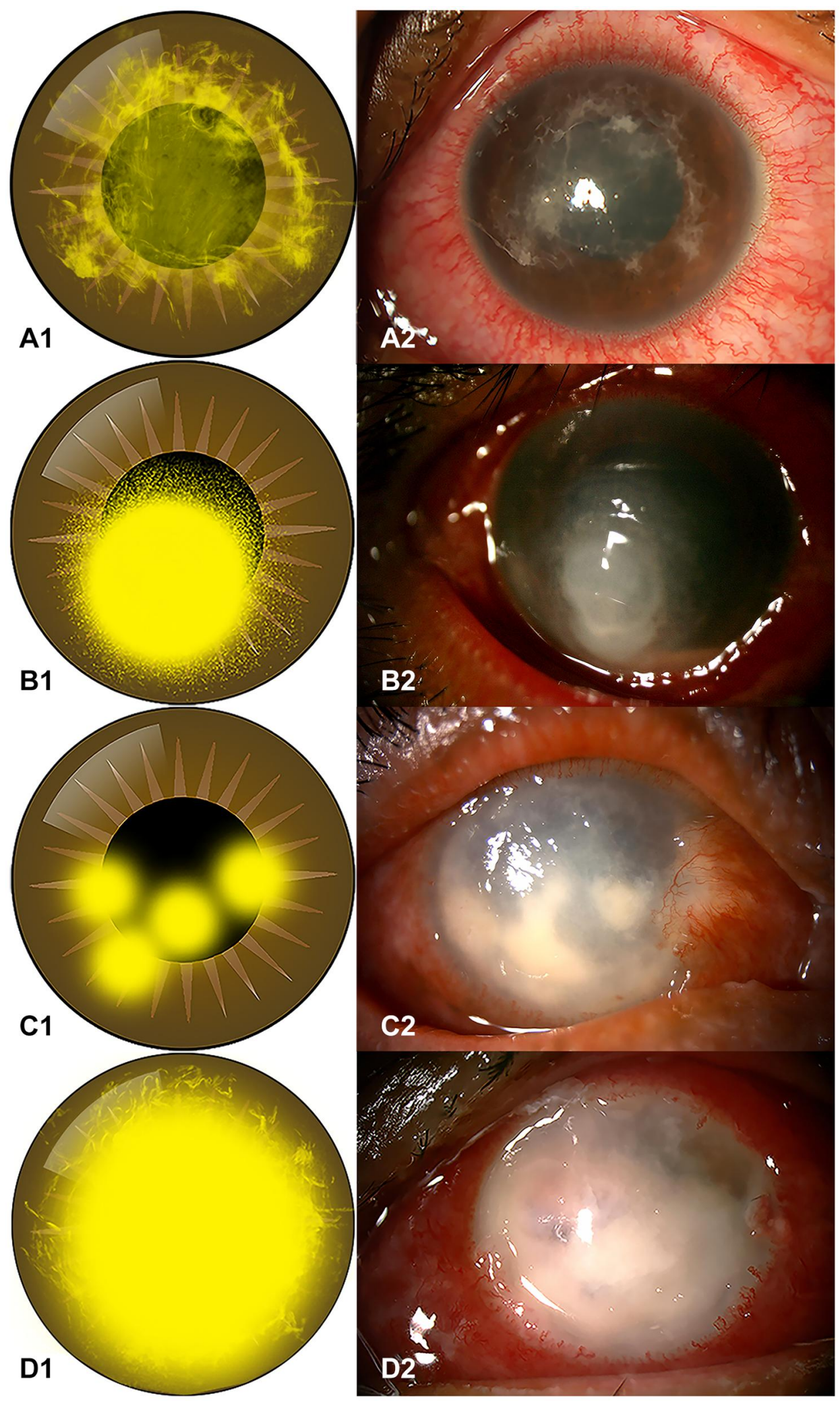

Figure I Diagrams of infiltration pattern and clinical slit-lamp photographs. (AI and A2) Diagram of a reticular infiltration pattern and a photograph of a 2 I-year-old student who had a history of contact-lens wearing and presented at KCMH two days after left eye irritation (Case\#2I); (BI and B2) diagram of a satellite infiltration pattern and a photograph of a 55-year-old farmer who had a trauma to the right eye from grass leaves (Case\#I5); (CI and C2) diagram of a multifocal infiltration pattern and a photograph of a 58-year-old farmer who had a trauma of the right eye with soil contamination (Case\#24); (DI and D2) diagram of a total infiltration pattern and a photograph of the right eye of a 6I-year-old female without a significant history of ocular trauma (Case\#I0). 
(c) Multifocal infiltration: scattered multi-focal dense infiltrations (Figure 1C);

(d) Total infiltration: dense infiltration of the total cornea (Figure 1D).

The baseline characteristics, laboratory results, and the clinical course of all patients are summarized in Table 2.

\section{Treatment and Outcomes}

Most patients received a combination of at least two antifungal agents either at $\mathrm{KCMH}$ or at outside clinics, prior to referral. The most commonly used topical regimen was $5 \%$ natamycin and $1 \%$ voriconazole (14 eyes; $53.8 \%$ ), followed by $5 \%$ natamycin and $0.17 \%$ amphotericin B (11 eyes; $42.3 \%$ ). Topical antibiotics, such as $0.5 \%$ moxifloxacin (15 eyes), $1 \%$ azithromycin ( 5 eyes), and $0.2 \%$ linezolid ( 3 eyes)

Table 2 Clinical and Diagnostic Data

\begin{tabular}{|l|c|}
\hline Ocular Features & No. of Eyes (\%) \\
\hline Best corrected visual acuity (BCVA) & \\
Worse than 20/200 & $24 / 26(92.3)$ \\
$20 / 40$ to 20/200 & $2 / 26(7.7)$ \\
\hline Pattern of infiltration & \\
Reticular & $11 / 24(45.8)$ \\
Satellite & $10 / 24(41.7)$ \\
Multifocal & $2 / 24(8.3)$ \\
Total infiltration & $1 / 24(4.2)$ \\
\hline Maximal diameter of infiltration area (mm) (mean \pm SD) & $5.56 \pm 1.94$ \\
\hline Depth of infiltration & \\
Anterior to mid stroma & $11 / 23(47.8)$ \\
Posterior stroma & $12 / 23(52.2)$ \\
\hline Presence of epithelial defect & $23 / 26(88.5)$ \\
\hline Presence of hypopyon & $14 / 26(53.8)$ \\
\hline Diagnostic laboratory & \\
Positive culture & $1 / 25(4)$ \\
Positive PCR & $4 / 25(16)$ \\
Positive culture, genus and species confirmed by PCR & $20 / 25(80)$ \\
\hline PIAl injection & $17 / 26(65.4)$ \\
In globe salvage case & $1 / 17(41.2)$ \\
In globe removal case & $10 / 17(58.8)$ \\
\hline Surgical interventions & \\
Corneal biopsy & $15 / 26(526(38.5)$ \\
\hline TPK & \\
\hline Evisceration or enucleation & $5 / 26(57.7)$ \\
\hline Treatment outcome & \\
Globe salvage & \\
Globe removal & \\
\hline
\end{tabular}

were also used. The treatment of 15 eyes $(57.7 \%)$ also included oral terbinafine and itraconazole. Two eyes (7.7\%) in two patients responded well to medical treatment alone (cases 6 and 25), and the treatment regimens in these cases are described in Supplementary Table 1.

The infection progressed in 24 eyes (92.3\%) despite drug treatment. Twenty-one eyes underwent TPK, and three eyes had to be eviscerated because of uncontrollable disease. The average duration from disease onset to the first TPK was $28.9 \pm 14.6$ days. After the first TPK, 6 of 21 eyes (28.6\%) improved, and no subsequent surgery was needed until the patients' discharge. Recurrence was observed in 15 of 21 eyes (71.4\%). In seven of these (46.7\%), we performed evisceration or enucleation and in the other eight (53.3\%), a second TPK. Three eyes improved after the second TPK, while another five eyes had to undergo evisceration or enucleation.

Overall, globe salvage was possible in 11 eyes (42.3\%), whereas the globe had to be removed in 15 $(57.7 \%)$ eyes. Seventeen eyes had received at least one dose of PIAI (Table 2).

The anatomy was preserved in all globe salvage patients, but the visual outcomes were mostly poor (the best corrected visual acuity (BCVA) ranged from hand movements to 20/ $25)$. The BCVA of $20 / 25$ achieved in a patient with anterior stromal reticular infiltration who had BCVA of 20/50 at presentation. The details of the clinical characteristics, medical, surgical, and adjunctive management, and treatment outcomes are shown in Supplementary Table 1.

\section{Factors Affecting the Treatment Outcome}

We compared the demographic data, ocular features, and histopathological characteristics between the globe salvage group and the globe removal group in Tables 3 and 4 . The box plot analysis showed that there was a statistically significant difference in the duration of the disease from onset to the first medical treatment between the two groups $(P=0.02)$ (Figure 2). Nine of 11 cases in the globe salvage group received their first medical treatment on day one after the onset of symptoms.

\section{Histopathological Features}

Extensive infiltration of the cornea with acute inflammatory cells, extensive cellular necrosis, and stromal collagen lamellar fragmentation was found in all specimens. The most common microscopic characteristics of 
Table 3 Demographic Data and histopathology of Globe Salvage Group versus Globe Removal Group (Categorical Variables)

\begin{tabular}{|c|c|c|c|c|}
\hline A. Assessment of Predisposing Factors & $\begin{array}{l}\text { Globe Salvage n(\%), } \\
\qquad \mathrm{N}=\mathrm{I} \text { I }\end{array}$ & $\begin{array}{c}\text { Globe Removal n } \\
\text { (\%), } N=15\end{array}$ & $\begin{array}{l}\text { Risk Ratio for } \\
\text { Globe Removal }\end{array}$ & $\begin{array}{l}95 \% \mathrm{Cl} \text { of } \\
\text { Risk Ratio }\end{array}$ \\
\hline \multicolumn{5}{|l|}{ History of water contamination } \\
\hline Presence & $3(27.3)$ & $9(60.0)$ & 1.75 & 0.88 to 3.48 \\
\hline Absence & 8 (72.7) & $6(40.0$ & & \\
\hline \multicolumn{5}{|c|}{$\begin{array}{l}\text { History of eye contamination with natural substances } \\
\text { (ie, soil or plant materials) }\end{array}$} \\
\hline Presence & $2(18.2)$ & II (73.3) & 2.75 & 1.18 to 6.42 \\
\hline Absence & $9(81.8)$ & $4(26.7)$ & & \\
\hline \multicolumn{5}{|l|}{ History of ocular injury } \\
\hline Presence & I (9.1) & $9(60.0)$ & 2.40 & I.23 to 4.67 \\
\hline Absence & $10(90.9)$ & $6(40.0)$ & & \\
\hline \multicolumn{5}{|l|}{$\begin{array}{l}\text { Duration from onset of symptoms to Ist medical } \\
\text { treatment }\end{array}$} \\
\hline$>$ I day & $2(18.2)$ & II (73.3) & 2.75 & I. 18 to 6.42 \\
\hline$\leq$ I day & $9(81.8)$ & $4(26.7)$ & & \\
\hline B. Clinical Characteristics & $\begin{array}{c}\text { Globe Salvage } \\
\text { n (\%) }\end{array}$ & $\begin{array}{c}\text { Globe Removal } \\
\text { n (\%) }\end{array}$ & $\begin{array}{l}\text { Risk Ratio for } \\
\text { Globe Removal }\end{array}$ & $\begin{array}{l}\text { 95\% Cl of } \\
\text { Risk Ratio }\end{array}$ \\
\hline Pattern of infiltration & $N=I I$ & $N=13$ & & \\
\hline Satellite/Multifocal/Total & $3(27.3)$ & $10(76.9)$ & 2.82 & 1.03 to 7.74 \\
\hline Reticular & $8(72.7)$ & $3(23.1)$ & & \\
\hline Maximal diameter of infiltration area & $N=10$ & $N=15$ & & \\
\hline$\geq 6 \mathrm{~mm}$ diameter & $2(20.0)$ & $12(80.0)$ & 3.14 & I. 17 to 8.45 \\
\hline$<6 \mathrm{~mm}$ diameter & $8(80.0)$ & $3(20.0)$ & & \\
\hline Depth of infiltration & $N=I I$ & $\mathrm{~N}=12$ & & \\
\hline Posterior stroma & $3(27.3)$ & $9(75.0)$ & 2.75 & 0.99 to 7.62 \\
\hline Anterior-middle stroma & $8(72.7)$ & $3(25.0)$ & & \\
\hline Epithelial defect & $N=I I$ & $N=15$ & & \\
\hline Presence & $9(8 \mid .8)$ & $14(93.3)$ & 1.83 & 0.36 to 9.35 \\
\hline Absence & $2(18.2)$ & $\mathrm{I}(6.7)$ & & \\
\hline Hypopyon & $N=I I$ & $N=15$ & & \\
\hline Presence & $2(18.2)$ & $12(80.0)$ & 3.43 & 1.26 to 9.35 \\
\hline Absence & $9(81.8)$ & $3(20.0)$ & & \\
\hline C. Histopathological Features & $\begin{array}{c}\text { Globe Salvage } \\
\text { n (\%) }\end{array}$ & $\begin{array}{c}\text { Globe Removal } \\
\text { n (\%) }\end{array}$ & $\begin{array}{l}\text { Risk Ratio for } \\
\text { Globe Removal }\end{array}$ & $\begin{array}{l}95 \% \mathrm{Cl} \text { of } \\
\text { Risk Ratio }\end{array}$ \\
\hline Descemet membrane & $N=7$ & $N=I I$ & & \\
\hline Involved/Perforated/Detached & $3(42.9)$ & $6(54.5)$ & 1.20 & 0.57 to 2.53 \\
\hline Intact & $4(57.1)$ & $5(45.5)$ & & \\
\hline Depth of organism invasion & $N=6$ & $N=12$ & & \\
\hline Posterior stroma & $3(50.0)$ & $9(75.0)$ & 1.5 & 0.63 to 3.56 \\
\hline Anterior to mid stroma & $3(50.0)$ & $3(25.0)$ & & \\
\hline Depth of inflammatory cell presence & $N=8$ & $N=11$ & & \\
\hline Posterior stroma & $7(87.5)$ & $8(72.7)$ & 0.71 & 0.34 to 1.49 \\
\hline Anterior to mid stroma & I (I2.5) & $3(27.3)$ & & \\
\hline
\end{tabular}

Notes: Boldface type highlights a significant risk ratio as determined by $95 \%$ confidence interval (Cl). 
Table 4 Demographic Data and Histopathology of Globe Salvage Group versus Globe Removal Group (Continuous Variables)

\begin{tabular}{|c|c|c|c|c|c|}
\hline Characteristics & $\begin{array}{l}\text { Globe Salvage } \\
\qquad \mathbf{N}=\mathbf{I} \text { I }\end{array}$ & $\begin{array}{l}\text { Globe Removal } \\
\qquad \mathbf{N}=15\end{array}$ & $\begin{array}{c}\text { Mean } \\
\text { Difference }\end{array}$ & $\begin{array}{l}95 \% \mathrm{Cl} \text { of Mean } \\
\text { Difference }\end{array}$ & $P$ value \\
\hline \multicolumn{6}{|l|}{ Demographic data } \\
\hline Age at onset [mean $\pm S D$; years] & $36.6 \pm 13.1$ & $53.1 \pm 10.3$ & 16.43 & 6.98 to 25.88 & $0.00^{\mathrm{a}}$ \\
\hline \multirow[t]{2}{*}{$\begin{array}{l}\text { Duration from onset of symptoms to Ist medical treatment } \\
\left.\text { [median; days }\left(\mathrm{IQR}^{\dagger}\right)\right]\end{array}$} & $I(1,2)$ & $5(3,11)$ & & & $0.02^{b}$ \\
\hline & $N=9$ & $\mathrm{~N}=12$ & & & \\
\hline Duration from onset of symptoms to Ist TPK [mean \pm SD; days] & $28.6 \pm 14.0$ & $29.1 \pm 15.6$ & 0.53 & -13.28 to 14.34 & $0.94^{\mathrm{a}}$ \\
\hline \multicolumn{6}{|l|}{ Histopathological features } \\
\hline & $N=7$ & $N=\mid 1$ & & & \\
\hline Estimated density of organism (Median; filament per HPF${ }^{\ddagger}(I Q R)$ ) & $107(16,260)$ & $376(323,620)$ & & & $0.03^{b}$ \\
\hline
\end{tabular}

Notes: ${ }^{\dagger} \mathrm{IQR}$, Interquartile range. ${ }^{\ddagger} \mathrm{HPF}$, High-power field. $P<0.05$ are highlighted in boldface. ${ }^{\mathrm{a}} P$ value of independent $t$-test. ${ }^{\mathrm{b}} P$ value of Mann-Whitney $U$-test.

P. insidiosum were rarely branching and sparsely septate short hyphae that varied in size and diameter. In every specimen, $P$. insidiosum hyphae showed intense positive staining with Gomori methenamine silver. Pythium hyphae were much denser in the globe removal group (Figure 3-5).

\section{Discussion}

In this retrospective study, we aimed to identify the predictive factors for treatment outcomes in patients with Pythium keratitis. We found that the risk of globe removal increased with age, delayed initial topical antifungal or antibiotic treatment, advanced disease at

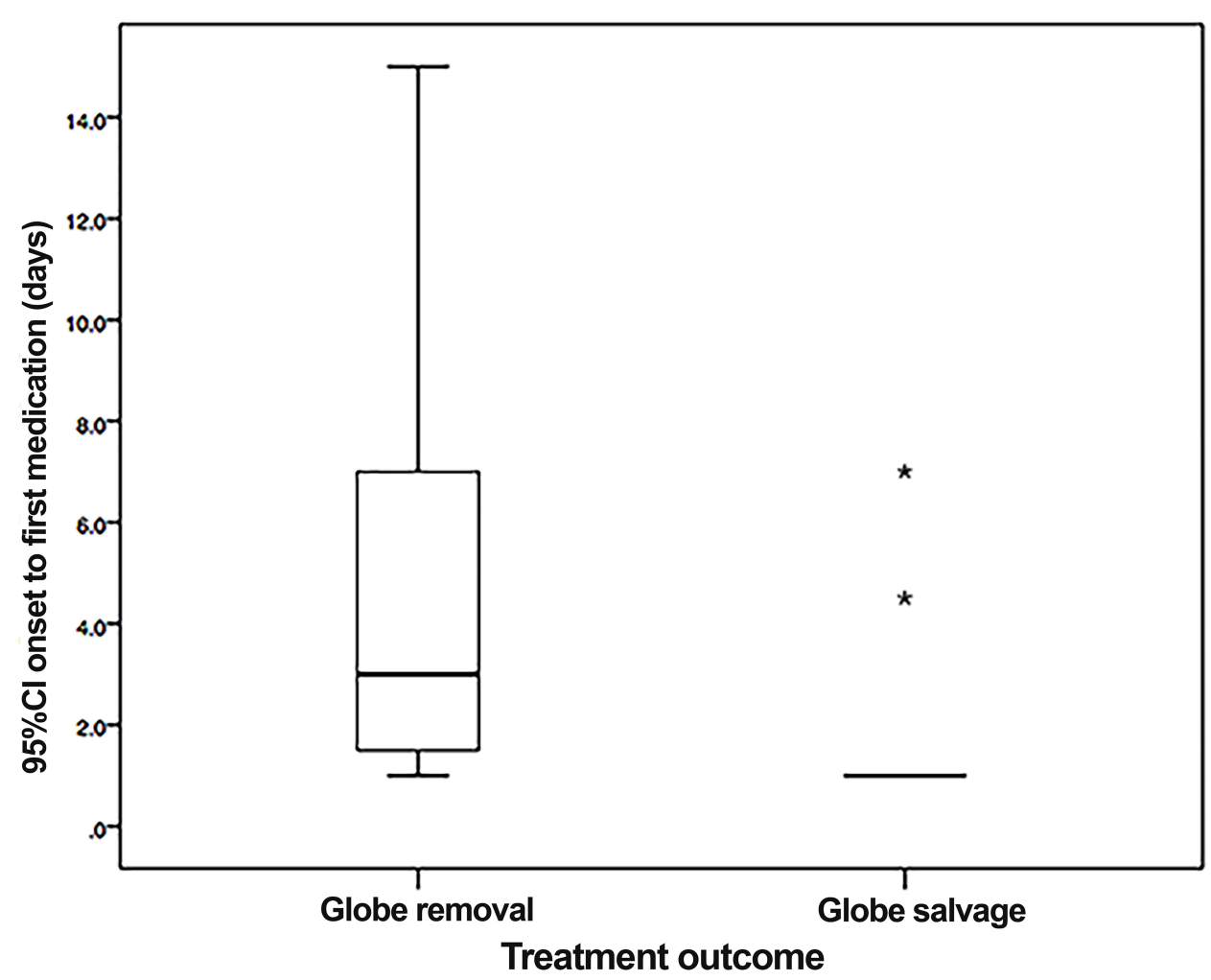

Figure 2 Box plot demonstrates that almost all of the cases from the globe salvage group received their first medical treatment on day I after onset of symptoms (asterisks indicate extreme outliers). 


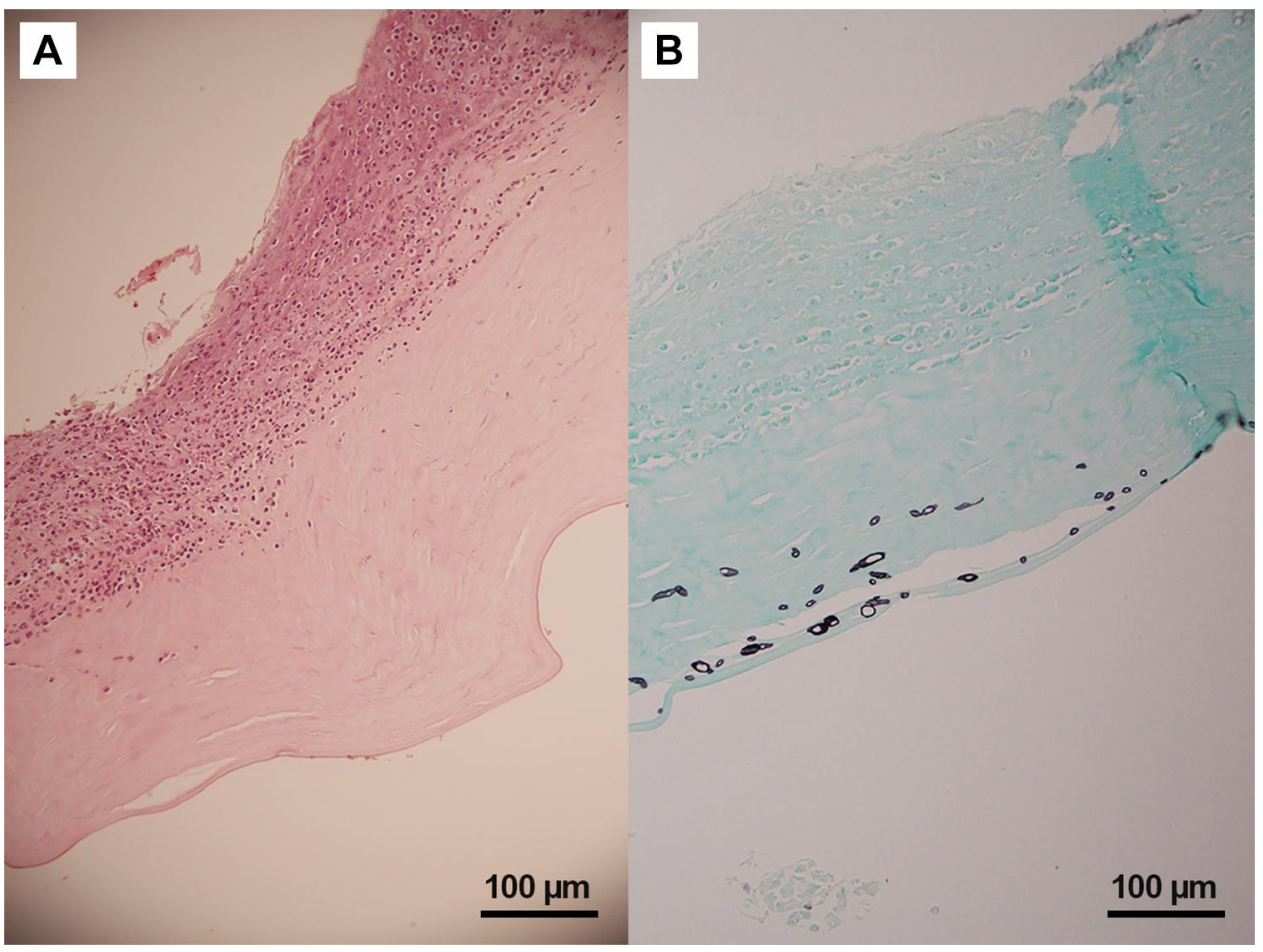

Figure 3 Histopathology of Pythium keratitis in a globe salvage case (Case\#19). (A) Histopathology section shows an ulcerated corneal lesion with numerous acute inflammatory cells and necrotic cells primarily located at the anterior stroma (Hematoxylin-Eosin); (B) special stain shows varying sizes of short hyphae at the posterior stroma and pre-Descemet's membrane area (Gomori Methenamine Silver).

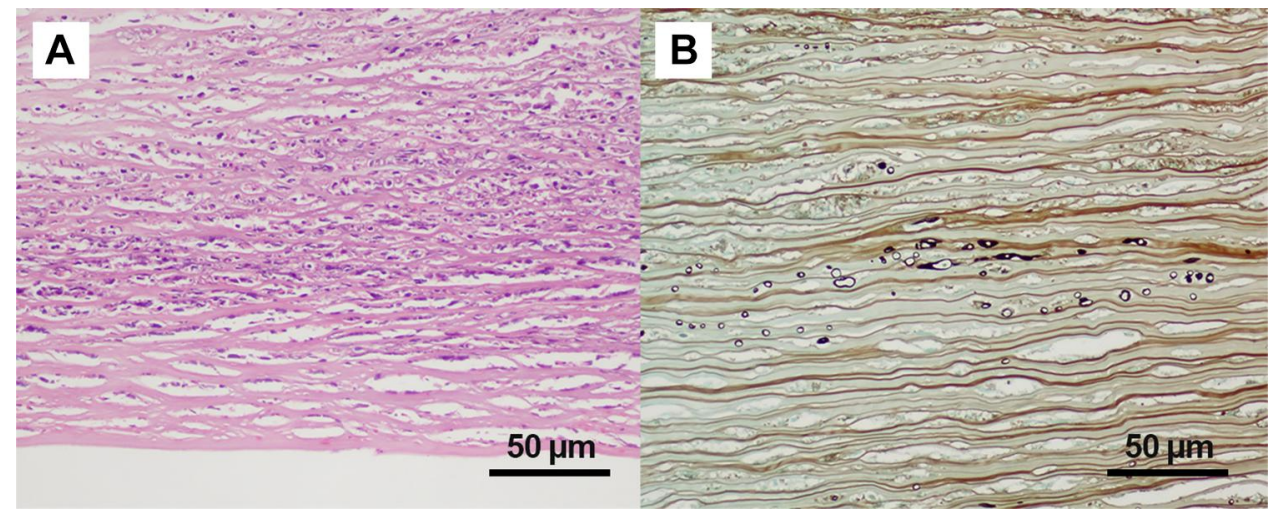

Figure 4 Histopathology of Pythium keratitis in globe salvage case (Case\#05). (A) Histopathology section shows numerous acute inflammatory cells and necrotic cells in the corneal stroma (Hematoxylin-Eosin); (B) special stain shows varying-sized short hyphae at the mid stroma (Gomori Methenamine Silver).

presentation, and dense Pythium hyphae infiltration. All previous studies of Pythium keratitis were either small or large case series. A retrospective study from South India reported a series of 71 patients with microbiologically proven Pythium keratitis. ${ }^{1}$ The authors concluded that there was still a knowledge gap regarding the best treatment because conventional antifungal agents are not effective against $P$. insidiosum. Newer treatments such as linezolid, azithromycin, and PIAI were reported to be successful in healing the infection in small case series ${ }^{8,16}$ and in vitro susceptibility testing. ${ }^{22}$ Currently, TPK remains the most effective treatment but has to be done as early as possible. However, recurrence of the infection and graft failure are still problematic, frequently necessitating regrafting. In our series, we reported $42.3 \%$ of globe salvage, which is higher than in previous reports in Thailand. ${ }^{3,4,17}$ The exception was a 2019 report from Permpalung et $\mathrm{al}^{8}$ who achieved globe salvage in $53 \%$ of 


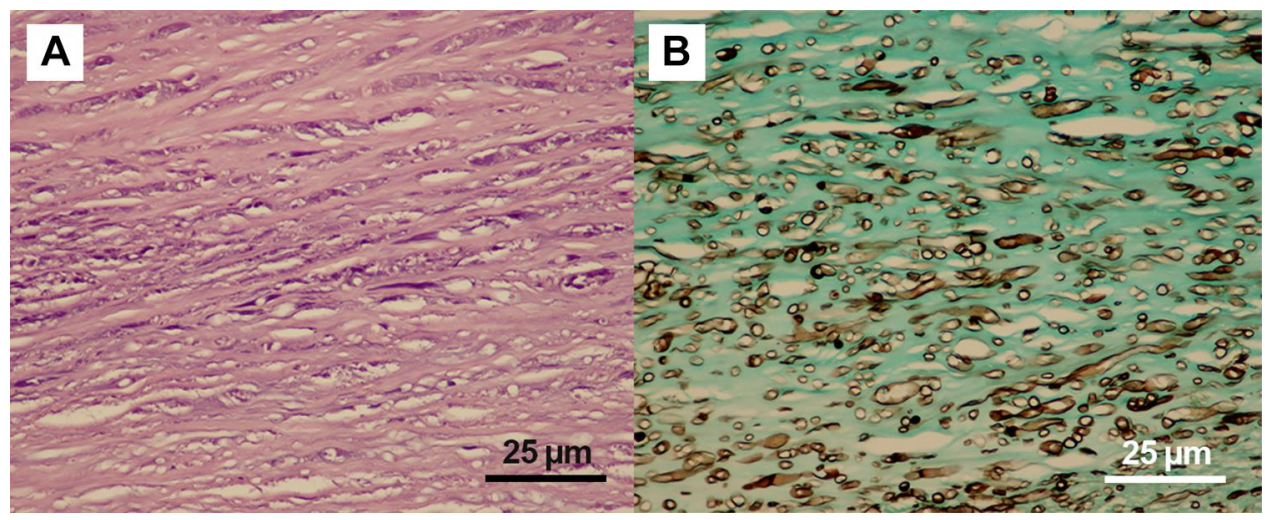

Figure 5 Histopathology of Pythium keratitis in globe removal case (Case\#23). (A) Histopathology section shows numerous acute inflammatory cells and necrotic cells in the corneal stroma (Hematoxylin-Eosin); (B) special stain shows numerous varying-sized short hyphae with rare septation (Gomori Methenamine Silver).

patients. The authors found that patients in whom the globe was salvaged were significantly younger and showed a shorter period from the onset of disease to first ocular surgery than those in whom the globe had to be removed. However, their study focused on PIAI treatment and the profile of biologic markers after treatment.

\section{Clinical Characteristics}

Most patients were referred to $\mathrm{KCMH}$ from hospitals in the Eastern region of Thailand. According to previous reports from other regions in Thailand (ie, North, ${ }^{23}$ Northeast, ${ }^{2}$ and South ${ }^{4}$ ), the organism is widespread across the country. Although the natural habitat of $P$. insidiosum is soil and water, only $58 \%$ of the patients in our study were agriculturist, $46 \%$ had a history of water contamination, and $50 \%$ had a history of environmental exposure to natural substances, such as soil or plant material. This implies that Pythium keratitis may occur in patients who do not have a history of exposure to water. Most of the patients in our report had advanced disease: $92 \%$ had a visual acuity of less than 20/200, and 52.2\% had deep stromal infiltration. Considering that, the globe salvage rate of $42 \%$ in our study is acceptable compared to other reports from Thailand, where it ranged from $21 \%$ to $53.3 \% .^{3,4,8}$

\section{Factors Affecting the Treatment Outcome}

Patients who had to have their globe removed were significantly older than those in whom it could be preserved (mean 53.1 vs 36.6 years). This finding was consistent with previous reports. ${ }^{3,8}$ Regarding impaired natural immune responses in older patients, infectious condition tends to cause more morbidity in this group. We also found a higher risk of globe removal in patients who had a history of ocular injury or contamination of their eyes with natural substances. It is possible that these two characteristics are confounding factors because infection in patients whose eyes were exposed to natural substances mostly involved a traumatic mechanism. This finding is consistent with reports from India ${ }^{1}$ describing that the majority of their patients had environmental exposures not involving water. Considering these data, we suggest that Pythium keratitis should be suspected in patients with findings suggestive of $P$. insidiosum who had disease persisting despite antifungal treatment even though there is no clear history of exposure to water.

We also found that patients who received treatment late had an approximately 2.75-times higher risk of globe removal. Contrary to a recent report, ${ }^{8}$ we did not find that patients who received early ocular surgery, especially TPK, had better outcomes. One reason may be differences in the study populations. All of our patients were referred to us from other hospitals, meaning they already had advanced disease at their first presentation. It is difficult to eradicate the infection in an advanced clinical stage with TPK.

Pythium keratitis is recognized for its progressive course. Within a few days, the infection may spread all over the cornea and invade the posterior stroma, causing corneal perforation. The unique histopathological patterns of Pythium keratitis were previously described as multiple tentacle-like or reticular infiltrations originating from the central lesion. Hence, we distinguished four specific patterns of corneal lesions in our patients and used these to 
investigate a potential association with the treatment outcome. We found that there was a significantly higher risk for globe removal in patients who had a large lesion (diameter $\geq 6 \mathrm{~mm}$ ). Interestingly, the risk of globe removal also increased by 2.8 -times in patients who had satellite, multifocal, or total corneal infiltration patterns compared to those that had a reticular pattern. In spite of not statistically significant, our result showed the risk of globe removal increased 2.75-times in eyes with posterior stromal infiltration. We conclude that a large lesion and satellite, multifocal, and total corneal infiltration patterns represent an advanced stage of disease, and these were associated with a poor treatment outcome in our study. A hypopyon is common in Pythium keratitis, ranging from $25 \%$ to $54 \%$ in previous studies, ${ }^{1}$ where it was found to be a factor for a poor prognosis. In our study, a hypopyon was associated with a 3.4-times higher risk for evisceration or enucleation compared to that in patients without a hypopyon. To date, the origin of the hypopyon in Pythium keratitis, ie, whether it comes from inflammation or infection, is unclear.

\section{Histopathology}

Our observations correspond to a previous report ${ }^{24}$ that found that the risk of globe removal increases with the density of fungal hyphae in the cornea specimens as an indication of advanced disease. Other histopathological parameters, such as the discontinuation of Descemet's membrane and the depth of $P$. insidiosum invasion and inflammatory cell infiltration in the first corneal specimen of patients diagnosed with Pythium keratitis, were not statistically significantly associated with the treatment outcome.

\section{Treatment and Outcome}

In our patients, only two $(7.7 \%)$ patients were successfully treated with medication only. Both patients had good initial visual acuity (20/40 and 20/50) and received treatment within one day after the onset of symptoms.

In our study, $28.6 \%$ of patients had a successful outcome, defined as globe preservation, after the first TPK, whereas previous studies reported a success rate of $30-80 \% .^{1,3,9,11,25}$ Our comparably low success rate might result from the advanced stage of disease with which patients in our study presented initially.

Since PIAI was administered at various points in time to our patients, we refrained from the statistical analysis of this variable and are not able to gauge the effects of this treatment. Furthermore, treatment with PIAI may not be effective in eradicating the infection in patients with advanced disease, as reported by Permpalung et al. ${ }^{8}$ In our patients, this treatment was safe and well-tolerated with no severe adverse events.

Our results need to be interpreted within the limitations of our study. First, this was a retrospective file review. Some data were missing in patients' documents. Further, our center is a referral center so that most of the patients presented with advanced stages of disease. Hence, our findings may not be representative of the presentation of Pythium keratitis in Thailand. Finally, Pythium keratitis has a low incidence. Even though we were able to identify some prognostic factors, our sample size was not large enough to allow for multivariable analysis. Prospective studies in larger populations are required to obtain more accurate information on the prognosis and identify the most effective treatment for this severe infection.

\section{Conclusion}

Pythium keratitis is a sight-threatening disease that frequently requires globe removal. Early recognition and treatment of the disease, particularly among elderly patients, are critical to successfully eradicate the infection. Advanced stages of disease and delay of drug therapy result in a high risk of globe removal. The histopathological analysis may provide important prognostic information.

\section{Acknowledgments}

We would like to acknowledge Assist. Prof. Lalida Pariyakanok MD, Department of Ophthalmology, Faculty of Medicine, Chulalongkorn University, Bangkok, Thailand, for her assistance, and Prof. Stephen John Kerr, PhD., Biostatistics Excellence Center, Department of Research Affairs, Faculty of Medicine, Chulalongkorn University, Bangkok, Thailand, and Assoc. Prof. Dr. Jaranit Kaewkungwal, Department of Tropical Hygiene, Faculty of Tropical Medicine, Mahidol University, for their guidance in the study design, statistics and interpretation of the results.

\section{Disclosure}

The authors have no conflicts of interest to declare.

\section{References}

1. Hasika R, Lalitha P, Radhakrishnan N, Rameshkumar G, Prajna NV, Srinivasan M. Pythium keratitis in South India: incidence, clinical profile, management, and treatment recommendation. Indian $J$ Ophthalmol. 2019;67(1):42-47. doi:10.4103/ijo.IJO_445_18 
2. Thanathanee O, Enkvetchakul O, Rangsin R, Waraasawapati S, Samerpitak K, Suwan-apichon O. Outbreak of Pythium keratitis during rainy season: a case series. Cornea. 2013;32(2):199-204. doi:10.1097/ICO.0b013e3182535841

3. Permpalung N, Worasilchai N, Plongla R, et al. Treatment outcomes of surgery, antifungal therapy and immunotherapy in ocular and vascular human pythiosis: a retrospective study of 18 patients. $J$ Antimicrob Chemother. 2015;70(6):1885-1892. doi:10.1093/jac/ dkv008

4. Krajaejun T, Sathapatayavongs B, Pracharktam R, et al. Clinical and epidemiological analyses of human pythiosis in Thailand. Clin Infect Dis. 2006;43(5):569-576. doi:10.1086/506353

5. Mendoza L, Hernandez F, Ajello L. Life cycle of the human and animal oomycete pathogen Pythium insidiosum. J Clin Microbiol. 1993;31(11):2967-2973. doi:10.1128/JCM.31.11.2967-2973.1993

6. Lekhanont K, Chuckpaiwong V, Chongtrakool P, Aroonroch R, Vongthongsri A. Pythium insidiosum keratitis in contact lens wear: a case report. Cornea. 2009;28(10):1173-1177. doi:10.1097/ ICO.0b013e318199fa41

7. Lelievre L, Borderie V, Garcia-Hermoso D, et al. Imported Pythium insidiosum keratitis after a swim in Thailand by a contact lenswearing traveler. Am J Trop Med Hyg. 2015;92(2):270-273. doi:10.4269/ajtmh.14-0380

8. Permpalung N, Worasilchai N, Manothummetha $\mathrm{K}$, et al. Clinical outcomes in ocular pythiosis patients treated with a combination therapy protocol in Thailand: a prospective study. Med Mycol. 2019;57(8):923-928. doi:10.1093/mmy/myz013

9. Sharma S, Balne PK, Motukupally SR, et al. Pythium insidiosum keratitis: clinical profile and role of DNA sequencing and zoospore formation in diagnosis. Cornea. 2015;34(4):438-442. doi:10.1097/ ICO.0000000000000349

10. He H, Liu H, Chen X, Wu J, He M, Zhong X. Diagnosis and treatment of Pythium insidiosum corneal ulcer in a chinese child: a case Report and literature Review. Am J Case Rep. 2016;17:982-988. doi:10.12659/AJCR.901158

11. Agarwal S, Iyer G, Srinivasan B, Agarwal M. Panchalam Sampath Kumar S, Therese LK. Clinical profile of Pythium keratitis: perioperative measures to reduce risk of recurrence. $\mathrm{Br} J$ Ophthalmol. 2018;102(2):153-157. doi:10.1136/bjophthalmol-2017-310604

12. Bagga B, Sharma S, Madhuri Guda SJ, et al. Leap forward in the treatment of Pythium insidiosum keratitis. Br J Ophthalmol. 2018;102 (12):1629-1633. doi:10.1136/bjophthalmol-2017-311360

13. Chitasombat MN, Jongkhajornpong P, Lekhanont K, Krajaejun T. Recent update in diagnosis and treatment of human pythiosis PeerJ. 2020;8:e8555. doi:10.7717/peerj.8555

14. Mendoza L, Vilela R. The mammalian pathogenic oomycetes. Curr Fungal Infect Rep. 2013;7.
15. Ramappa M, Nagpal R, Sharma S, Chaurasia S. successful medical management of presumptive Pythium insidiosum keratitis. Cornea. 2017;36(4):511-514. doi:10.1097/ICO.0000000000001162

16. Maeno S, Oie Y, Sunada A, et al. Successful medical management of Pythium insidiosum keratitis using a combination of minocycline, linezolid, and chloramphenicol. Am J Ophthalmol Case Rep. 2019;15:100498. doi:10.1016/j.ajoc.2019.100498

17. Krajaejun T, Pracharktam R, Wongwaisayawan S, Rochanawutinon M, Kunakorn M, Kunavisarut S. Ocular pythiosis: is it under-diagnosed? Am J Ophthalmol. 2004;137(2):370-372. doi:10.1016/S00029394(03)00908-5

18. Mendoza L, Mandy W, Glass R. An improved Pythium insidiosumvaccine formulation with enhanced immunotherapeutic properties in horses and dogs with pythiosis. Vaccine. 2003;21(21-22):2797-2804. doi:10.1016/S0264-410X(03)00225-1

19. Jones DB. Decision-making in the management of microbial keratitis. Ophthalmology. 1981;88(8):814-820. doi:10.1016/S0161-6420(81) 34943-4

20. Chindamporn A, Vilela R, Hoag KA, Mendoza L. Antibodies in the sera of host species with pythiosis recognize a variety of unique immunogens in geographically divergent Pythium insidiosum strains. Clin Vaccine Immunol. 2009;16(3):330-336. doi:10.1128/ CVI.00429-08

21. Kammarnjesadakul P, Palaga T, Sritunyalucksana K, et al. Phylogenetic analysis of Pythium insidiosum Thai strains using cytochrome oxidase II (COX II) DNA coding sequences and internal transcribed spacer regions (ITS). Med Mycol. 2011;49(3):289-295. doi:10.3109/13693786.2010.511282

22. Worasilchai N, Chindamporn A, Plongla R, et al. In vitro susceptibility of Thai Pythium insidiosum isolates to antibacterial agents. Antimicrob Agents Chemother. 2020;64(4):e02099-02019. doi:10.1128/AAC.02099-19

23. Vanittanakom N, Supabandhu J, Khamwan C, et al. Identification of emerging human-pathogenic Pythium insidiosum by serological and molecular assay-based methods. J Clin Microbiol. 2004;42(9):3970_ 3974. doi:10.1128/JCM.42.9.3970-3974.2004

24. Vemuganti GK, Garg P, Gopinathan U, et al. Evaluation of agent and host factors in progression of mycotic keratitis: a histologic and microbiologic study of 167 corneal buttons. Ophthalmology. 2002;109(8):1538-1546. doi:10.1016/S0161-6420(02)01088-6

25. Agarwal S, Iyer G, Srinivasan B, et al. Clinical profile, risk factors and outcome of medical, surgical and adjunct interventions in patients with Pythium insidiosum keratitis. $\mathrm{Br} J$ Ophthalmol. 2019;103(3):296-300. doi:10.1136/bjophthalmol-2017-311804
Clinical Ophthalmology

\section{Publish your work in this journal}

Clinical Ophthalmology is an international, peer-reviewed journal covering all subspecialties within ophthalmology. Key topics include: Optometry; Visual science; Pharmacology and drug therapy in eye diseases; Basic Sciences; Primary and Secondary eye care; Patient Safety and Quality of Care Improvements. This journal is indexed on PubMed
Central and CAS, and is the official journal of The Society of Clinical Ophthalmology (SCO). The manuscript management system is completely online and includes a very quick and fair peer-review system, which is all easy to use. Visit http://www.dovepress.com/ testimonials.php to read real quotes from published authors. 